Article

\title{
Surface Treatments on the Characteristics of Metal-Oxide Semiconductor Capacitors
}

\author{
Ray-Hua Horng $1,2, * \mathbb{C}$, Ming-Chun Tseng ${ }^{3}$ and Dong-Sing Wuu ${ }^{3}[$ \\ 1 Institute of Electronics, National Chiao Tung University, Hsinchu 300, Taiwan \\ 2 Center for Emergent Functional Matter Science, National Chiao Tung University, Hsinchu 300, Taiwan \\ 3 Department of Materials Science and Engineering, National Chung Hsing University, Taichung 402, Taiwan; \\ idt266@yahoo.com.tw (M.-C.T.); dsw@nchu.edu.tw (D.-S.W.) \\ * Correspondence: rhh@nctu.edu.tw Tel: +886-3-5712121 (ext. 54138)
}

Received: 29 November 2018; Accepted: 17 December 2018; Published: 20 December 2018

check for updates

\begin{abstract}
The properties of metal-oxide semiconductor (MOS) capacitors with different chemical treatments have been examined in this study. A MOS capacitor consists of an $\mathrm{Al}_{2} \mathrm{O}_{3} / \mathrm{n}-\mathrm{GaN} / \mathrm{AlN}$ buffer/Si substrate. Four chemical treatments, containing organic solvents, oxygen plasma and $\mathrm{BCl}_{3}$ plasma, dilute acidic and alkali solvents, and hydrofluoric acid, were used to reduce the metal ions, native oxides, and organic contaminants. The $\mathrm{n}-\mathrm{GaN}$ surface was treated with these chemical treatments before $\mathrm{Al}_{2} \mathrm{O}_{3}$ was grown on the treated n-GaN surface to reduce the interface state trap density $\left(D_{i t}\right)$. The value of $D_{i t}$ was calculated using the capacitance-voltage curve at $1 \mathrm{MHz}$. The $D_{i t}$ of a $\mathrm{u}-\mathrm{GaN}$ surface was modified using various solutions, which further influenced the contact properties of GaN.
\end{abstract}

Keywords: chemical treatment; capacitor; interface state trap density

\section{Introduction}

Surface cleaning treatments are the foundation of a semiconductor device fabrication process [1,2]. Surface cleaning significantly affects the epitaxial defects [2], metal contact resistance/stability [3], and overall device quality of GaN-based devices [4]. Evaluating surface cleanliness requires considering the electrical properties of the device, structure, and interface state trap of the surface. Moreover, a surface treatment is used to remove the native oxides, organic contaminants, metal ions, particulates, residual species, and weaknesses in atomic bonding.

Recently, AlGaN/GaN high electron mobility transistors (HEMTs) were demonstrated for use in power electronic devices. In an HEMT device, a high saturation current, low leakage current, and high transconductance are necessary. Therefore, a low-resistance ohmic contact and low interface state trap density $\left(D_{i t}\right)$ must be obtained for an HEMT device. Interface states may cause various operational stability and reliability drawbacks in GaN-based HEMTs such as threshold voltage instability [4] and current collapse phenomena [5]. A surface treatment not only improves the device performance but also enhances the ohmic contact characteristics of GaN with metals [3].

In addition, surface treatments have been proposed to improve the ohmic contact properties between a low work function metal contact and a GaN or AlGaN surface. N vacancies are created during surface treatment and act as shallow donors for electrons and increase the surface doping concentration to overcome the Schottky barrier height for carrier transport. Therefore, improving the contact properties and reducing contact degradation are crucial for an AlGaN/GaN HEMT. A poor surface quality causes surface defects and contamination of the interface states, which originate from dangling bonds. The surface chemical treatment is not the only way to improve AlGaN/GaN HEMT device performance. The phosphorus-based annealing processes $\left(\mathrm{POCl}_{3}, \mathrm{P}_{2} \mathrm{O}_{5}\right)$ also modified 
surface conditions before dielectrics material deposition to further modify the AlGaN/GaN HEMT [6]. The metal-oxide-semiconductor HEMTs(MOS-HEMTs) structure using different dielectrics material causes different device performance of MOS-HEMTs, such as different $\mathrm{C}-\mathrm{V}$ characteristics, specific resistance $\left(\mathrm{R}_{\mathrm{on}}\right)$, breakdown voltage, $D_{i t}$ value, saturation drain current of the devices [7]. The MOS-HEMTs structure using $\mathrm{Al}_{2} \mathrm{O}_{3}$ [8] will be effective to enhance the breakdown voltage generated from the gate leakage. The ALD is a surface-controlled layer-by-layer process for the deposition of thin films with atomic layer accuracy. The $\mathrm{Al}_{2} \mathrm{O}_{3}$ used for MOS-HEMTs not only improve the basic electronic properties but also show low leakage current and high breakdown voltage. In this study, four chemical pretreatments were used for MOS capacitors before atomic layer deposition (ALD) of $\mathrm{Al}_{2} \mathrm{O}_{3}$ to modify the surface quality. The characteristics of MOS capacitors and the ohmic contact characteristics of $\mathrm{GaN}$ with the four chemical treatments are discussed.

\section{Experiments}

Figure 1 presents a schematic of an MOS capacitor. The MOS capacitor was grown on silicon (111) substrate through metal-organic chemical vapor deposition. The MOS capacitor consisted of an AlN nucleation layer, $2 \mu \mathrm{m}$ GaN buffer layer, and $1 \mu \mathrm{m} n-G a N$ layer Figure 1. Dilute $\mathrm{HCl}$ was used to remove the native oxides, and an organic solution was then used to remove organic contaminants in an ultrasonic cleaner before the MOS capacitor fabrication process. Mesa isolation was achieved using inductively coupled plasma-reactive ion etching with $\mathrm{BCl}_{3} / \mathrm{Cl}_{2} / \mathrm{Ar}$ plasma, and the sample was subjected to four chemical pretreatments before $\mathrm{Al}_{2} \mathrm{O}_{3}$ oxide layer deposition. The four chemical pretreatments are shown in Table 1.

Table 1. The four chemical pretreatment descriptions.

\begin{tabular}{|c|c|}
\hline Treatment & Description of Surface Treatment \\
\hline 1 & $\mathrm{ACE} \rightarrow \mathrm{IPA} \rightarrow$ DI Water $\rightarrow \mathrm{O}_{2}$ Plasma \\
\hline 2 & $\mathrm{ACE} \rightarrow \mathrm{IPA} \rightarrow$ DI Water $\rightarrow \mathrm{O}_{2}$ Plasma $\rightarrow \mathrm{HCl}: \mathrm{H}_{2} \mathrm{O}$ for $1 \mathrm{~min} \rightarrow$ DI Water $\rightarrow \mathrm{HF}: \mathrm{H}_{2} \mathrm{O}$ for 1 min \\
\hline 3 & $\begin{array}{l}\mathrm{ACE} \rightarrow \mathrm{IPA} \rightarrow \text { DI Water } \rightarrow \mathrm{O}_{2} \text { Plasma } \rightarrow \mathrm{BCl}_{3} \text { Plasma } \rightarrow \mathrm{HCl}: \mathrm{H}_{2} \mathrm{O} \text { for } 1 \mathrm{~min} \rightarrow \text { DI Water } \rightarrow \\
\mathrm{HF}: \mathrm{H}_{2} \mathrm{O} \text { for } 1 \text { min }\end{array}$ \\
\hline 4 & $\begin{array}{l}\mathrm{ACE} \rightarrow \mathrm{IPA} \rightarrow \text { DI Water } \rightarrow \mathrm{O}_{2} \text { Plasma } \rightarrow \text { HF: } \mathrm{H}_{2} \mathrm{O} \text { for } 1 \mathrm{~min} \rightarrow \text { DI Water } \rightarrow \mathrm{NH}_{4} \mathrm{OH}: \mathrm{H}_{2} \mathrm{O} \text { for } \\
1 \mathrm{~min} \rightarrow \text { DI Water } \rightarrow \text { HF: } \mathrm{H}_{2} \mathrm{O} \text { for } 1 \mathrm{~min} \rightarrow \text { DI Water } \rightarrow \mathrm{HCl}: \mathrm{H}_{2} \mathrm{O} \text { for } 1 \mathrm{~min} \rightarrow \text { DI Water } \rightarrow \\
\mathrm{HF}: \mathrm{H}_{2} \mathrm{O} \text { for } 1 \mathrm{~min}\end{array}$ \\
\hline
\end{tabular}

Subsequently, a 50-nm-thick $\mathrm{Al}_{2} \mathrm{O}_{3}$ layer as a gate oxide was deposited using ALD at $300{ }^{\circ} \mathrm{C}$ under 6 mbar. In the ALD process, water vapor and trimethylaluminum were respectively used as $\mathrm{O}$ and $\mathrm{Al}$ sources, which were alternate pulse forms, resulting in the formation of the $\mathrm{Al}_{2} \mathrm{O}_{3}$ layer. $\mathrm{Ti} / \mathrm{Al} / \mathrm{Ti} / \mathrm{Au}(25 \mathrm{~nm} / 125 \mathrm{~nm} / 45 \mathrm{~nm} / 55 \mathrm{~nm})$ alloyed for an ohmic contact with n-GaN was then formed through rapid thermal annealing (RTA) at $870{ }^{\circ} \mathrm{C}$ for $30 \mathrm{~s}$ in $\mathrm{N}_{2}$ ambient. Finally, Ni/Au metal was deposited on the $\mathrm{Al}_{2} \mathrm{O}_{3}$ by using an E-gun evaporating system. The contact characteristics of $\mathrm{Ti} / \mathrm{Al} / \mathrm{Ti} / \mathrm{Au}$ deposited on the $\mathrm{GaN}$ were evaluated by circular transmission line model (CTLM). The CTLM structure's inner and outer circle were 50, 100, 150, 200, and $250 \mu \mathrm{m}$, respectively. The inner radius of the pad was $100 \mu \mathrm{m}$. 


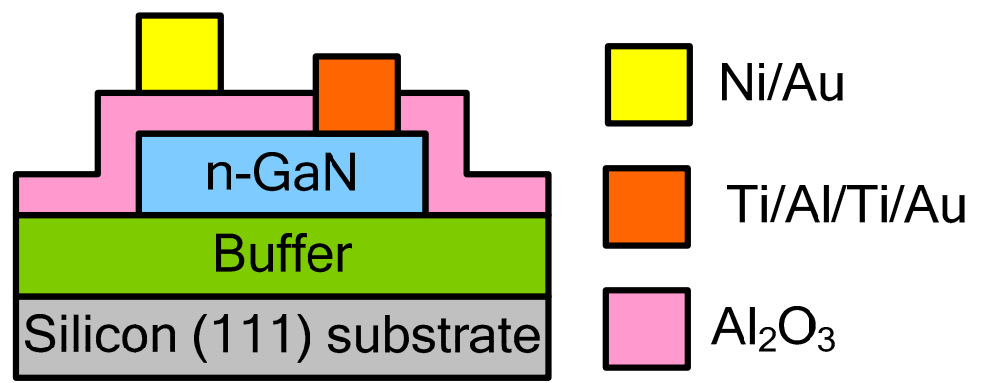

Figure 1. Schematic of an MOS capacitor.

The chemical bonding states on the GaN surface were characterized using X-ray photoelectron spectroscopy (XPS) with a monochromate Al K $\alpha$ X-ray (energy; $1486.6 \mathrm{eV}$ ). The shift in the XPS spectra was calibrated using a charge neutralization gun because of surface charge accumulation by emitting photoelectrons. The angle between the incident photons and the detected photoelectrons was set at $45^{\circ}$, which is sensitive to an analysis of surface chemical states.

\section{Results and Discussion}

The hysteresis behavior of capacitance-voltage $(\mathrm{C}-\mathrm{V})$ curves is strongly correlated to the trap density at the $\mathrm{GaN} / \mathrm{Al}_{2} \mathrm{O}_{3}$ interface of a MOS capacitor. Figure 2 shows the hysteresis behavior of the $\mathrm{C}-\mathrm{V}$ curves of MOS capacitors treated with various chemical treatments. Obviously, the MOS capacitor treated with treatment 1 exhibited the largest amount of hysteresis. Treatment 1 consisted of an organic solvent and $\mathrm{O}_{2}$ plasma, which were used to remove particles from the air ambiance, and stripped residual photoresist and organic contaminants. The dangling bond, weaknesses in atomic bonding, and native oxides are difficult to remove using treatment 1 . Generally, they are removed by complexes composed of organic and inorganic solvents, such as treatments $2-4$.
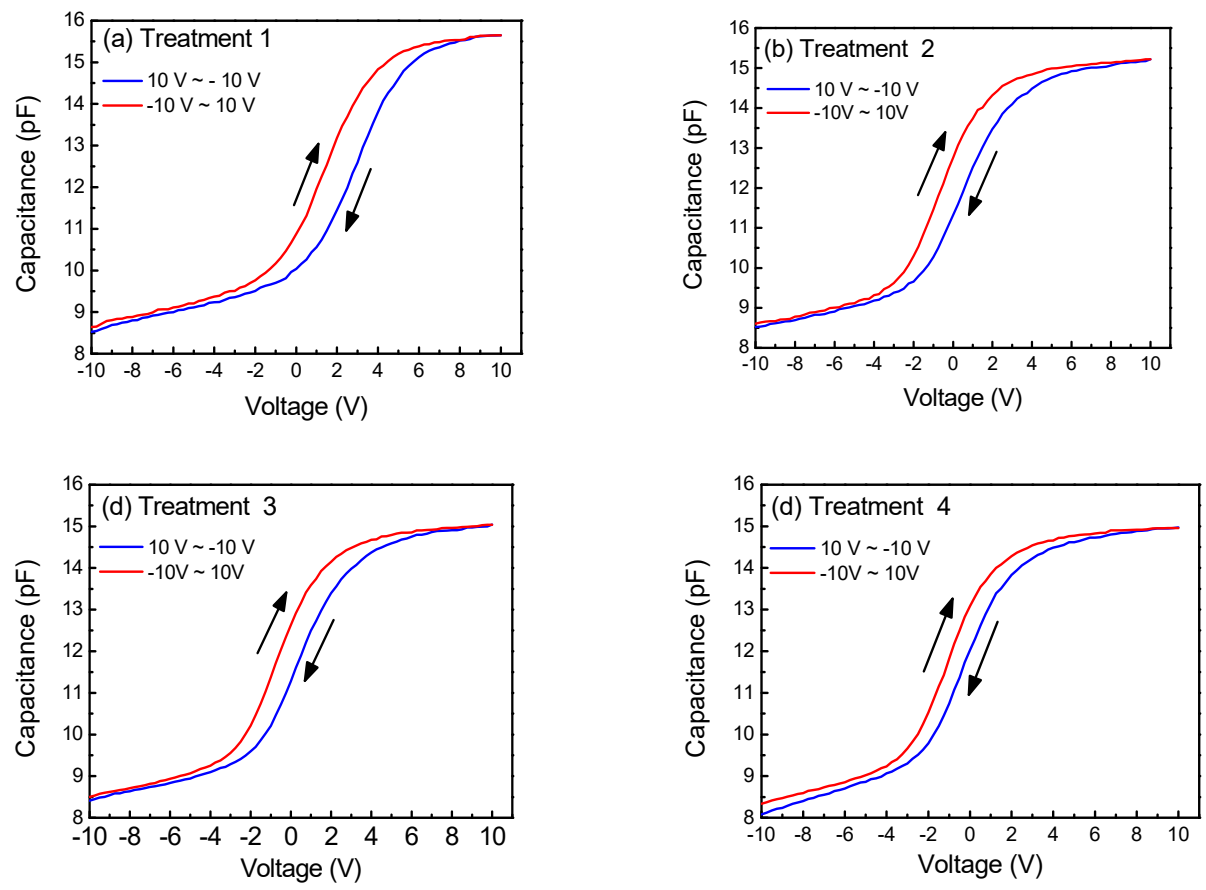

Figure 2. The Capacitance-voltage curves of MOS capacitors treated with (a) treatment 1 , (b) treatment 2, (c) treatment 3 , and (d) treatment 4 .

To calculate the $D_{i t}$ value, the oxide capacitance (capacitance at accumulation, $C_{o x}$ ) was measured using the $\mathrm{C}-\mathrm{V}$ curves. The flat band voltage $\left(V_{F B}\right)$ was calculated using Equation (1) to quantify the 
relative shifts for analyzing the hysteresis behavior of the capacitors; $V_{F B}$ was measured using the $\mathrm{C}-\mathrm{V}$ curves at a point of $C_{F B}$ obtained using [9]:

$$
C_{F B}=\frac{C_{o x} \varepsilon_{s} A / \lambda}{C_{o x}+\varepsilon_{s} A / \lambda}
$$

where $\varepsilon_{s}=9.5$ is the dielectric constant of $\mathrm{GaN}, \lambda=\left(\varepsilon_{s} \varepsilon_{0} k_{B} T / q^{2} N_{D}\right)^{1 / 2}$ is the Debye length of $\mathrm{n}$-GaN [10], $T$ is the absolute temperature, $q$ is the electron charge, $k_{B}$ is the Boltzmann constant, and $N_{D}=6 \times 10^{17} \mathrm{~cm}^{-3}$ is the electron concentration of $\mathrm{n}-\mathrm{GaN}$. The relative shifts in $V_{F B}$ during the sweep down $(10$ to $-10 \mathrm{~V})$ and up $(-10$ to $10 \mathrm{~V})$ for the surface treatments of $\mathrm{GaN}$ with various treatments are consistent with the presence of interface state trap densities at or near the $\mathrm{GaN} / \mathrm{Al}_{2} \mathrm{O}_{3}$ interface, which was based on the $\mathrm{C}-\mathrm{V}$ curve (Figure 2). The hysteresis at $V_{F B}$ (shift in $V_{F B}$ ) was used to approximate the interface state trap densities in each sample, according to the $\mathrm{C}-\mathrm{V}$ characteristics. The flat-band voltage $V_{F B}$ of the sample is shown in Table 2, and the threshold onset voltage $V_{t h}$ is obtained using [11]:

$$
V_{t h}=V_{F B}-2\left|\phi_{b}\right|-\frac{\sqrt{4 q \varepsilon_{s} \varepsilon_{o} N_{D} \mid \phi_{b}} \mid}{\varepsilon_{o x} \varepsilon_{o} / t_{o x}}
$$

where $\phi_{b}=\left(k_{B} T / q\right) \ln \left(N_{D} / n_{i}\right), n_{i}=2.0 \times 10^{-10} \mathrm{~cm}^{-3}$ is the intrinsic carrier concentration of GaN at room temperature [12], $\varepsilon_{o x}=9.9$ is the dielectric constant of $\mathrm{Al}_{2} \mathrm{O}_{3}$, and $t_{o x}$ is the thickness of the $\mathrm{Al}_{2} \mathrm{O}_{3}$ dielectric. The relative shift $\left(\Delta V_{t h}\right)$ is the variation in $V_{F B}$ during the sweep down (10 to $\left.-10 \mathrm{~V}\right)$ and up ( -10 to $10 \mathrm{~V}$ ) and is calculated using Equation (2) for the surface treatment of GaN with different treatments. A small voltage shift $\left(\Delta V_{t h}\right)$ is attributable to the different charging conditions of the interface states with different chemical treatments. The interface state trap densities $\left(D_{i t}\right)$ can be estimated using [13,14]:

$$
D_{i t}=\frac{C_{o x} \Delta V_{F B}(T)}{q}
$$

where $q$ and $C_{o x}$ are the electron charge and accumulation capacitance per unit of area, respectively. In the worst case scenario, treatment 1 showed a $D_{i t}$ value of $1.74 \times 10^{12} \mathrm{~cm}^{-2}$. The lowest $D_{i t}$, $8.30 \times 10^{11} \mathrm{~cm}^{-2}$, was obtained using treatment 4 . The $D_{i t}$ of $\mathrm{GaN}$ treated with treatment 4 was reduced by approximately $50 \%$ compared with that of $\mathrm{GaN}$ treated with treatment 1 . Treatment 4 consisted of $\mathrm{HF}, \mathrm{HCl}$, and $\mathrm{NH}_{4} \mathrm{OH}$, which is used for removing native oxides, metal ions, and organic contaminants of GaN. Therefore, the GaN surface treated with treatment 4 showed the cleanest surface, and the lowest $D_{i t}$ was obtained. The oxide capacitance (capacitance at accumulation, $C_{o x}$ ), flat band voltage $\left(V_{F B}\right)$, real thickness of $\mathrm{Al}_{2} \mathrm{O}_{3}$ measured using transmission electron microscopy, flat band capacitance $\left(C_{F B}\right)$, and interface state trap densities $\left(D_{i t}\right)$ are summarized in Table 2 . The different chemical treatment causes a different $D_{i t}$ value, the chemical treatment not only affects the $D_{i t}$, but also modified the $\mathrm{GaN}$ surface contact properties with $\mathrm{Ti} / \mathrm{Al} / \mathrm{Ti} / \mathrm{Au}$. Therefore, $D_{i t}$ value was related to surface contact resistance with $\mathrm{Ti} / \mathrm{Al} / \mathrm{Ti} / \mathrm{Au}$. The high $D_{i t}$ value will result in the contact resistance. Because the $D_{i t}$ value is sensitive to the GaN surface condition with different chemical treatment, in order to further understand the surface condition after chemical treatment, the XPS spectra analysis and XPS Ga-O/Ga-N ratio were used to explain the $D_{i t}$ value changed with different treatment recipes.

The chemical treatment technology modified the n-GaN surface, subsequent dielectrics material growth, contact resistance with metal material, and HEMT device performance. A circular transmission line model was used to evaluate the $\rho_{c}$ of $\mathrm{GaN}$ contacted with $\mathrm{Ti} / \mathrm{Al} / \mathrm{Ti} / \mathrm{Au}$. The results indicated that the $\rho_{c}$ of the samples treated with treatments $1-4$ were $2.77 \times 10^{-4}, 3.51 \times 10^{-4}, 2.63 \times 10^{-4}$, and $2.20 \times 10^{-4} \Omega-\mathrm{cm}^{2}$, respectively. The different $\rho_{c}$ value was related to the GaN surface barrier height, the details were described in Figure 5. The $\rho_{c}$ of GaN treated with treatment 4 was reduced by approximately $22 \%$ compared with that of GaN treated with treatment 1 . The contact characteristics of $\mathrm{GaN}$ with $\mathrm{Ti} / \mathrm{Al} / \mathrm{Ti} / \mathrm{Au}$ were affected by the coverage of oxide and carbon contaminants. Complex cleaning agents, such as treatments $2-4$, were used to remove or reduce the contaminants. Treatments 
2-4 contained $\mathrm{HCl}$ and $\mathrm{HF}$, which are known to remove oxides from Ga-based semiconductors [15]. However, $\mathrm{HCl}$ and $\mathrm{HF}$ wet-chemical pretreatments are more effective in producing the lowest coverage of oxide and carbon contaminants [16] to modify the contact characteristic of $\mathrm{GaN}$ with $\mathrm{Ti} / \mathrm{Al} / \mathrm{Ti} / \mathrm{Au}$. Treatment 4 consisted of an alkaline solution, acidic solution, and diluted HF, and was used to remove organic contaminants, metal ions, and native oxides. Notably, $\mathrm{NH}_{4} \mathrm{OH}: \mathrm{H}_{2} \mathrm{O}$ (1:3) predominantly removes gallium oxide $\left(\mathrm{Ga}_{2} \mathrm{O}_{3}\right)$ from the GaN surface [17] and organic contaminants, thus improving the adhesion ability of the metal film. Therefore, treatment 4 resulted in the lowest contamination and cleanest surface; thus, the lowest $\rho_{c}$ was obtained.

Table 2. The $C_{O x}, V_{F B}$, hysteresis at $V_{F B}$, and $D_{i t}$ of an MOS capacitor after different chemical treatments and the specific contact resistance $\left(\rho_{c}\right)$ of $\mathrm{GaN}$ contacted with $\mathrm{Ti} / \mathrm{Al} / \mathrm{Ti} / \mathrm{Au}$.

\begin{tabular}{ccccc}
\hline Item & Treatment 1 & Treatment 2 & Treatment 3 & Treatment 4 \\
\hline$C_{O x}(\mathrm{pF})$ & 15.6 & 15.1 & 14.9 & 14.9 \\
$C_{F B}(\mathrm{pF})$ & 13.98 & 13.57 & 13.41 & 13.41 \\
Hysteresis at $V_{F B}(\mathrm{~V})$ & 1.4 & 1.3 & 0.9 & 0.7 \\
$t_{o x}(\mathrm{~nm})($ Thickness observed by TEM) & 49.02 & 48.50 & 47.13 & 48.16 \\
$D_{i t}\left(\mathrm{~cm}^{-2}\right)$ & $1.74 \times 10^{11}$ & $1.56 \times 10^{12}$ & $1.07 \times 10^{12}$ & $8.30 \times 10^{11}$ \\
$\rho_{c}$ of CTLM $\left(\Omega-\mathrm{cm}^{2}\right)$ & $2.77 \times 10^{4}$ & $3.51 \times 10^{4}$ & $2.63 \times 10^{4}$ & $2.20 \times 10^{4}$ \\
\hline
\end{tabular}

The $\rho_{c}$ is related to the surface barrier height of the $\mathrm{GaN}$ surface. The $\mathrm{Ga}-\mathrm{O}$ to $\mathrm{Ga}-\mathrm{N}$ ratio of the Ga3d peak was used to facilitate the analysis of the surface barrier height of $\mathrm{GaN}$ through various chemical treatments. XPS was used to study the surface composition on the GaN surface by using different chemical treatments. Figure 3a-d shows the Ga3d core level of the XPS spectra. The Ga3d peaks of GaN obtained using treatments 1-4 appeared at 19.4, 19.4, 19.6, and $19.4 \mathrm{eV}$, respectively. A blue shift of approximately $0.2 \mathrm{eV}$ was observed toward the high binding energy in a sample treated with treatment 3, compared with samples treated with the other treatments. This type of shift is assumed to have been caused by the loss of $\mathrm{N}$ at the surface or the creation of $\mathrm{N}$ vacancies, which would increase the n-type doping at the surface [18]. In addition, the shift could have been caused by the $\mathrm{BCl}_{3}$ plasma. Moreover, the Ga3d of XPS spectra photoelectrons can be separated into $\mathrm{Ga}-\mathrm{O}$ and $\mathrm{Ga}-\mathrm{N}$ components for various treatments. The main peak at a binding energy of $19.3 \mathrm{eV}$ corresponded to the $\mathrm{Ga}-\mathrm{N}$ bond, and the second peak at $20.3 \mathrm{eV}$ corresponded to the $\mathrm{Ga}-\mathrm{O}$ bond, thus confirming the presence of $\mathrm{Ga}_{2} \mathrm{O}_{3}$ as the native oxide layer on top of the $\mathrm{GaN}$ layer. The intensity and area of the $\mathrm{Ga}-\mathrm{O}$ core level of the Ga3d peak after different treatments are functions of surface conditions. The Ga-O core level is reduced by a more complex chemical treatment association. The reduction of the $\mathrm{Ga}-\mathrm{O}$ core level indicated that the $\mathrm{Ga}_{2} \mathrm{O}_{3}$ layer was effectively removed or reduced. Otherwise, the remaining $\mathrm{Ga}_{2} \mathrm{O}_{3}$ layer might affect the quality of the ohmic contact and thus increase the contact resistance between $\mathrm{GaN}$ and metal.

Figure 4 shows the integrated $\mathrm{Ga}-\mathrm{O}$ core level levels, normalized using the Ga-N core level as a function of surface conditions to evaluate the residual native oxide layer on the GaN surface. The lowest $\mathrm{Ga}-\mathrm{O}$ to $\mathrm{Ga}-\mathrm{N}$ ratio of the Ga3d peak was obtained after treatment with treatment 4. Therefore, the $\rho_{c}$ of $\mathrm{GaN}$ contacted with $\mathrm{Ti} / \mathrm{Al} / \mathrm{Ti} / \mathrm{Au}$ was the lowest for the sample treated with treatment 4 . The area ratios of $\mathrm{Ga}-\mathrm{O}$ to $\mathrm{Ga}-\mathrm{N}$ obtained after different treatments are consistent with the contact characteristics of $\mathrm{GaN}$ with $\mathrm{Ti} / \mathrm{Al} / \mathrm{Ti} / \mathrm{Au}$ (Table 2). In addition, the peak ratio of $\mathrm{Ga}-\mathrm{O}$ to $\mathrm{Ga}-\mathrm{N}$ obtained using treatment 2 was the highest. This is because the $\mathrm{Ga}-\mathrm{O}$ area of $\mathrm{Ga} 3 \mathrm{~d}$ obtained using treatment 2 was the highest, resulting in a high contact resistance. The $\mathrm{Ga}-\mathrm{O}$ area was the highest because the fresh dangling bonds created by $\mathrm{O}_{2}$ plasma and trap more $\mathrm{O}_{2}$ existing in $\mathrm{HCl}: \mathrm{H}_{2} \mathrm{O}$ and $\mathrm{HF}: \mathrm{H}_{2} \mathrm{O}$ solutions. The $[\mathrm{Ga}-\mathrm{O}] /[\mathrm{Ga}-\mathrm{N}]$ ratios decreased because of the reduction in the $\mathrm{O}$ concentration and/or increase in the $\mathrm{N}$ concentration at the GaN surface [2]. In our study, samples treated with treatment 4 had the lowest $[\mathrm{Ga}-\mathrm{O}] /[\mathrm{Ga}-\mathrm{N}]$ ratio. After $\mathrm{O}_{2}$ plasma treatment, the residual $\mathrm{GaO}$ could be further etched by $\mathrm{HF}: \mathrm{H}_{2} \mathrm{O}$, following oxidation by $\mathrm{NH}_{4} \mathrm{OH}: \mathrm{H}_{2} \mathrm{O}$ and etched away by $\mathrm{HCl}: \mathrm{H}_{2} \mathrm{O}$ and $\mathrm{HF}: \mathrm{H}_{2} \mathrm{O}$. The $[\mathrm{Ga}-\mathrm{O}]$ decreased and $[\mathrm{Ga}-\mathrm{N}]$ increased during $\mathrm{GaO}$ etching. 

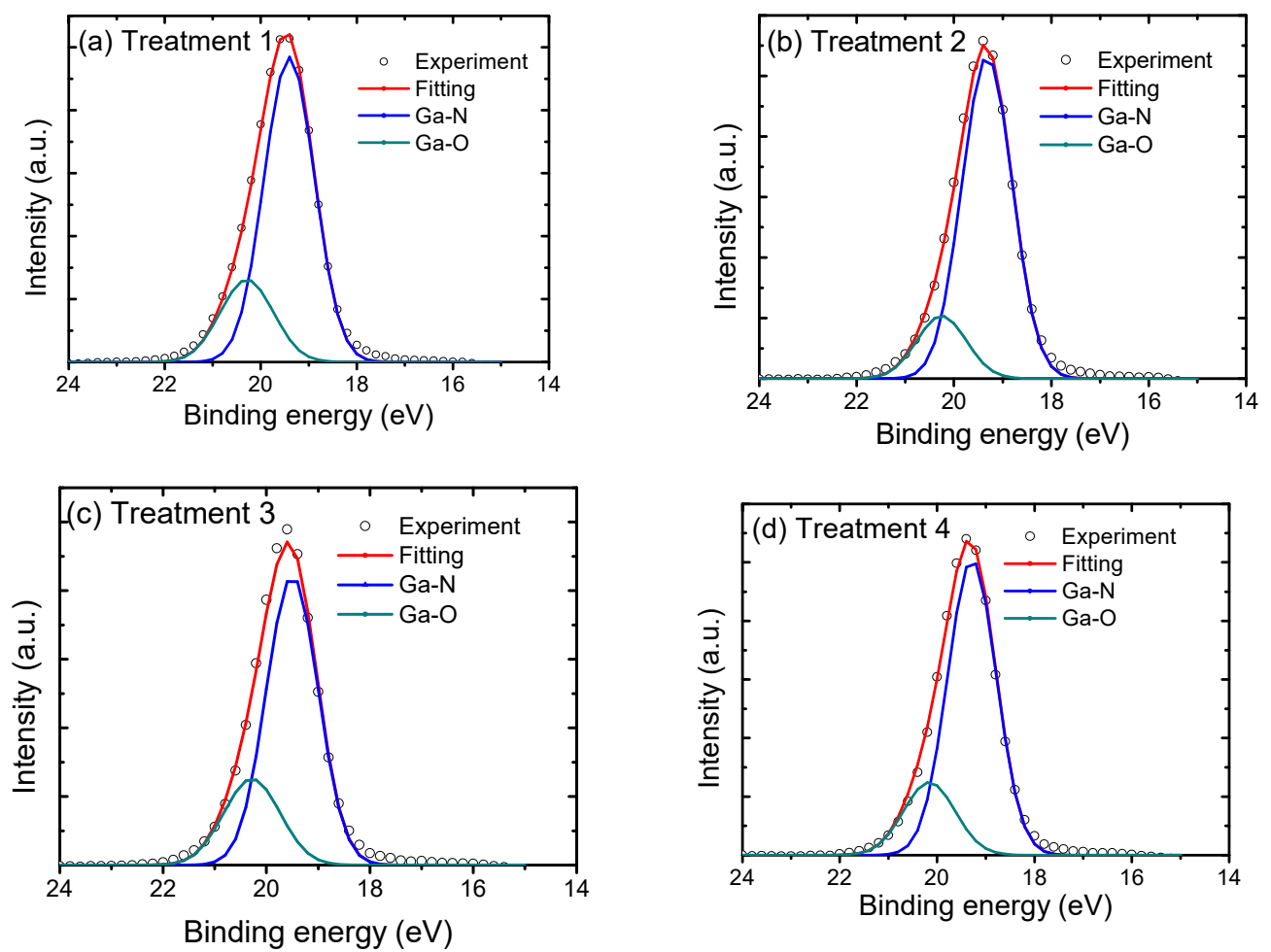

Figure 3. XPS spectra of the Ga3d core levels of the GaN layer after treatments with (a) treatment 1 , (b) treatment 2, (c) treatment 3 , and (d) treatment 4.

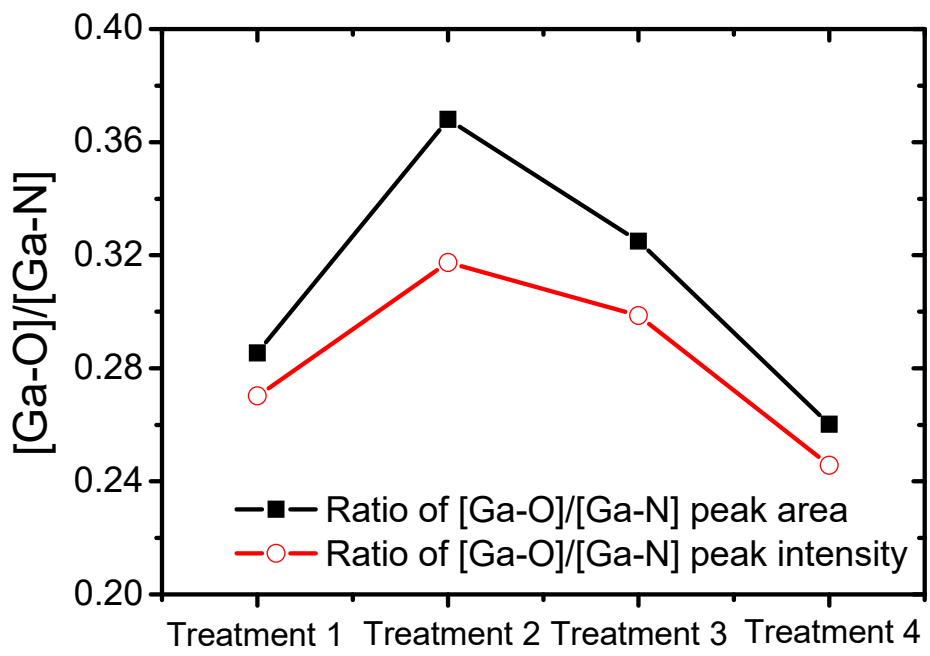

Figure 4. Ratio of $\mathrm{Ga}-\mathrm{O} / \mathrm{Ga}-\mathrm{N}$ obtained using the XPS spectra from the Ga3d core levels of the GaN layer.

Figure 5 shows the XPS valence band spectra of $\mathrm{GaN}$ treated with various treatments. A binding energy of $0 \mathrm{eV}$ on the horizontal axis corresponded to the energy position of the Fermi level $\left(E_{f}\right)$ at the surface. The energy position of the valence band maximum (VBM) was determined by linearly extrapolating the spectrum near the onset [19] to calculate the surface barrier height of GaN. The surface barrier height $\left(\Phi_{B}\right)$ is defined as $E_{c}-E_{f}$, where $E_{c}$ is the energy position of the conduction band minimum. The VBM of GaN treated with different treatments was lower than the Fermi level by approximately $1.68-2.26 \mathrm{eV}$. 

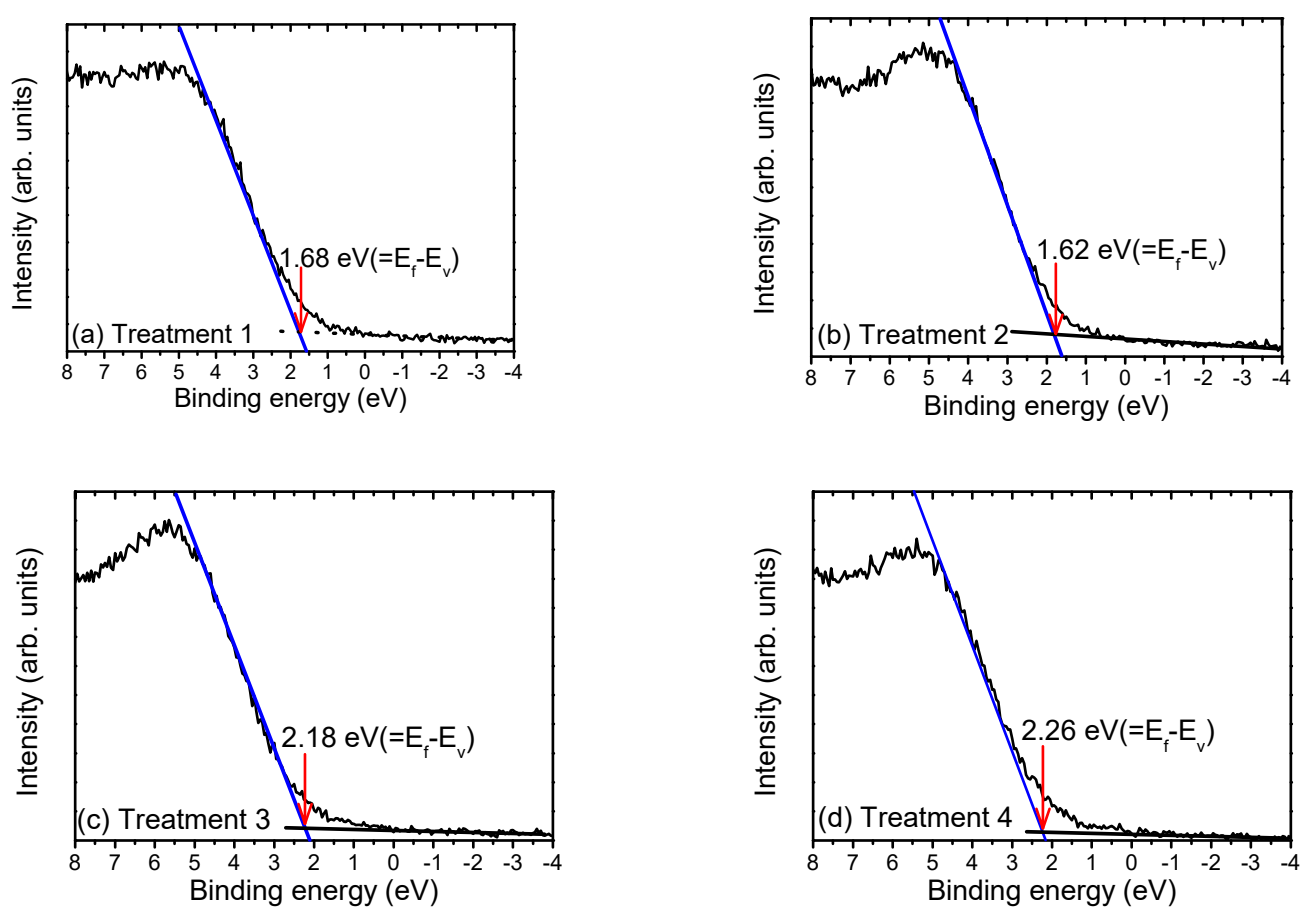

Figure 5. XPS valence band spectra of GaN after treatments with (a) treatment 1, (b) treatment 2, (c) treatment 3 , and $(\mathbf{d})$ treatment 4 .

The surface treatment of GaN modifies the GaN surface condition, including surface barrier height, binding energy and surface quality, which will further change the GaN ohmic contact properties with $\mathrm{Ti} / \mathrm{Al} / \mathrm{Ti} / \mathrm{Au}$. The XPS valence band and XPS spectra were powerful enough to determine the surface barrier height of GaN after treatment. The high surface barrier height caused the poor ohmic contact. The surface barrier height of GaN after treatment with treatment 1-4 is shown in Figure 6. The trend of the surface barrier height is consistent with that of the $\rho_{c}$. A high $\rho_{c}$ indicates a high surface barrier height of $\mathrm{GaN}$. The surface barrier height of the $\mathrm{GaN}$ surface after $\mathrm{BCl}_{3}$ plasma treatment (in treatment 3) was lower than that of $\mathrm{GaN}$ after the treatment 1 and 2 treatments. The $\mathrm{BCl}_{3}$ plasma increased the surface $\mathrm{N}$ vacancy of $\mathrm{GaN}$, which acts as a donor-type density for electrons, thus increasing the surface doping concentration [20]. The increase in the donor-type density of the GaN surface further improved the metallurgical process to reduce the surface barrier height of GaN during RTA. During RTA, Ti undergoes a metallurgical reaction with $\mathrm{GaN}$, forming interfacial nitrides such as TiN. This can cause the GaN subsurface below the TiN to be heavily doped (n-type) [21]. Therefore, the surface barrier height of GaN after treatment 3 was lower than that after treatments 1 and 2, and the surface barrier height of $\mathrm{GaN}$ after treatment 4 was the lowest. This result indicates that treatment 4 had the highest surface donor density, which contributed to a reduction in the ohmic contact resistance. A lower surface barrier height of $\mathrm{GaN}$ indicated a low contact resistance of $\mathrm{GaN}$ with $\mathrm{Ti} / \mathrm{Al} / \mathrm{Ti} / \mathrm{Au}$, thereby easily forming an ohmic contact for device applications. 


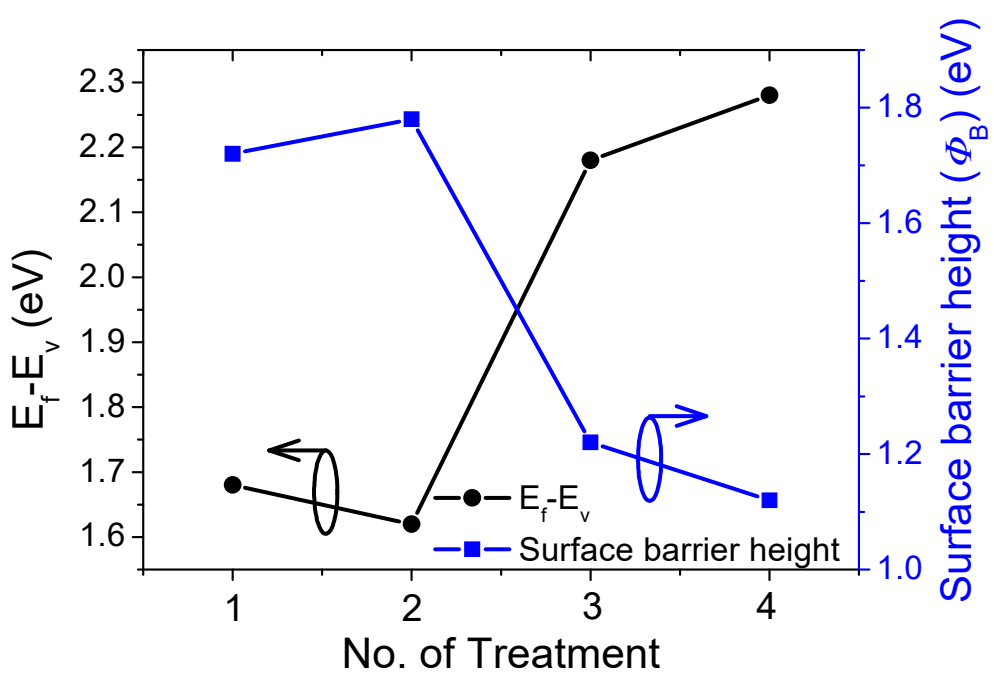

Figure 6. $E_{f}-E_{v}$ and surface barrier heights of GaN after treatments with treatment 1-4.

\section{Conclusions}

In summary, chemical treatments were successfully used to reduce the $D_{i t}$ and improve the surface quality. The lowest $D_{i t}$ of $8.30 \times 10^{11} \mathrm{~cm}^{-2}$ of the MOS capacitor was obtained when the sample was treated with treatment 4 because treatment 4 consisted of an alkaline solution, acidic solution, and diluted $\mathrm{HCl}$, and was used to remove organic contaminants, metal ions, and native oxides. The chemical solution treatment not only reduced the contamination but also introduced the donor density to change the ohmic contact property of $\mathrm{n}-\mathrm{GaN}$ with metal material.

Author Contributions: R.H. and D.W.; methodology, R.H., M.T. and D.W.; formal analysis, M.T.; investigation, D.W.; data curation, M.T.; writing-original draft preparation, R.H.; writing—review and editing, R.H. and D.W.; supervision, R.H.; project administration.

Funding: This research was funded by Ministry of Science and Technology under contract numbers MOST 107-2221-E-009-117-MY3, 107-2262-E-009-018-CC2, MOST107-3017-F009-003 and 105-2221-E-009-183-MY3.

Acknowledgments: This study was financially supported by the Ministry of Science and Technology under contract numbers MOST 107-2221-E-009-117-MY3, 107-2262-E-009-018-CC2 and 105-2221-E-009-183-MY3.

Conflicts of Interest: The authors declare no conflict of interest.

\section{References}

1. Kern, W. The Evolution of Silicon Wafer Cleaning Technology. J. Electrochem. Soc. 1990, 137, 1887-1990. [CrossRef]

2. Selvanathan, D.; Mohammed, F.M.; Bae, J.O.; Adesida, I.; Bogart, K.H.A. Investigation of surface treatment schemes on n-type $\mathrm{GaN}$ and $\mathrm{Al}_{0.20} \mathrm{Ga}_{0.80}$ N. J. Vac. Sci. Technol. B 2005, 23, 2538-2544. [CrossRef]

3. Cao, X.A.; Piao, H.; LeBoeuf, S.F.; Li, J.; Lin, J.Y.; Jiang, H.X. Effects of plasma treatment on the Ohmic characteristics of Ti/Al/Ti/Au contacts to n-AlGaN. Appl. Phys. Lett. 2006, 89, 082109. [CrossRef]

4. Hori, Y.; Yatabe, Z.; Hashizume, T. Characterization of interface states in $\mathrm{Al}_{2} \mathrm{O}_{3} / \mathrm{AlGaN} / \mathrm{GaN}$ structures for improved performance of high-electron-mobility transistors. J. Appl. Phys. 2013, 114, 244503. [CrossRef]

5. Vetury, R.; Zhang, N.Q.; Keller, S.; Mishra Umesh, K. The Impact of Surface States on the DC and RF Characteristics of AlGaN/GaN HFETs. IEEE Trans. Electron. Devices 2001, 48, 560-566. [CrossRef]

6. Roccaforte, F.; Fiorenza, P.; Greco, G.; Vivona, M.; Nigro, R.L.; Giannazzo, F.; Patti, A.; Saggio, M. Recent advances on dielectrics technology for SiCand GaN power devices. Appl. Surf. Sci. 2014, 301, 9-18. [CrossRef]

7. Hashizume, T.; Nishiguchi, K.; Kaneki, S.; Kuzmik, J.; Yatabe, Z. State of the art on gate insulation and surface passivation for GaN-based power HEMTs. Mater. Sci. Semicond. Proc. 2018, 78, 85-95. [CrossRef]

8. Schilirò, E.; Fiorenza, P.; Greco, G.; Roccaforte, F.; Nigro, R.L. Plasma enhanced atomic layer deposition of $\mathrm{Al}_{2} \mathrm{O}_{3}$ gate dielectric thin films on $\mathrm{AlGaN} / \mathrm{GaN}$ substrates: The role of surface predeposition treatments. J. Vac. Sci. Technol. A 2017, 35, 01B140. [CrossRef] 
9. Nicollian, E.H.; Brews, J.R. MOS (Metal Oxide Semiconductor) Physics and Technology; Wiley Publishers: New York, NY, USA, 1982; pp. 462-463. ISBN 978-0-471-43079-7.

10. Razeghi, M.; Rogalski, A. Semiconductor ultraviolet detectors. J. Appl. Phys. 1996, 79, 7433-7473. [CrossRef]

11. Muller, R.S.; Kamins, T.I. Device Electronics for Integrated Circuits, 2nd ed.; Wiley Publishers: New York, NY, USA, 1986; pp. 50-54, ISBN 9780471593980.

12. Casey, H.C., Jr.; Fountain, G.G.; Alley, R.G.; Keller, B.P.; DenBaars, S.P. Low interface trap density for remote plasma deposited $\mathrm{SiO}_{2}$ on n-type GaN. Appl. Phys. Lett. 1996, 68, 1850-1852. [CrossRef]

13. Fiorenza, P.; Greco, G.; Schilirò, E.; Iucolano, F.; Nigro, R.L.; Roccaforte, F. Determining oxide trapped charges in $\mathrm{Al}_{2} \mathrm{O}_{3}$ insulating films on recessed $\mathrm{AlGaN} / \mathrm{GaN}$ heterostructures by gate capacitance transients measurements. Jpn. J. Appl. Phys. 2018, 57, 050307. [CrossRef]

14. Schilirò, E.; Nigro, R.L.; Fiorenza, P.; Roccaforte, F. Negative charge trapping effects in $\mathrm{Al}_{2} \mathrm{O}_{3}$ films grown by atomic layer deposition onto thermally oxidized 4H-SiC. AIP Adv. 2016, 6, 075021. [CrossRef]

15. Wilmsen, C.W. Physics and Chemistry of III-V Compound Semiconductor Interfaces; Springer Publishers: New York, NY, USA; London, UK, 1985; pp. 1-72. ISBN 978-1-4684-4835-1.

16. Smith, L.L.; King, S.W.; Nemanich, R.J.; Davis, R.F. Cleaning of GaN surfaces. J. Electron. Mater. 1996, $25,805-810$. [CrossRef]

17. Prabhakaran, K.; Andersson, T.G.; Nozawa, K. Nature of native oxide on GaN surface and its reaction with Al. Appl. Phys. Lett. 1996, 69, 3213-3214. [CrossRef]

18. Ping, A.T.; Chen, Q.; Yang, J.W.; Khan, M.A.; Adesida, I. The effects of reactive ion etching-induced damage on the characteristics of ohmic contacts to n-Type GaN. J. Electron. Mater. 1998, 27, 261-265. [CrossRef]

19. Higashiwaki, M.; Chowdhury, S.; Swenson, B.L.; Mishra, U.K. Effects of oxidation on surface chemical states and barrier height of AlGaN/GaN heterostructures. Appl. Phys. Lett. 2010, 97, 222104. [CrossRef]

20. Fujishima, T.; Joglekar, S.; Piedra, D.; Lee, H.S.; Zhang, Y.; Uedono, A.; Palacios, T. Formation of low resistance ohmic contacts in $\mathrm{GaN}$-based high electron mobility transistors with $\mathrm{BCl}_{3}$ surface plasma treatment. Appl. Phys. Lett. 2009, 103, 083508. [CrossRef]

21. Kim, J.K.; Jang, H.W.; Lee, J.L. Mechanism for Ohmic contact formation of Ti on n-type GaN investigated using synchrotron radiation photoemission spectroscopy. J. Appl. Phys. 2002, 91, 9214-9217. [CrossRef]

(C) 2018 by the authors. Licensee MDPI, Basel, Switzerland. This article is an open access article distributed under the terms and conditions of the Creative Commons Attribution (CC BY) license (http://creativecommons.org/licenses/by/4.0/). 